\title{
Assessment of Quality of Life in Diabetes and Hypertensive Patients Attending Tertiary Care Hospitals in Khammam Region
}

\author{
Konda Nikhithaa,*, Sikilambatla Sai Kiran¹, Meraboina Prasad', Maram Chinna Eswaraiah² \\ 1Department of Pharmacy Practice, Anurag Pharmacy College, Ananthagiri, Suryapet, Telangana, INDIA. \\ 2Department of Pharmacognosy, Anurag Pharmacy College, Ananthagiri, Suryapet, Telangana, INDIA.
}

\begin{abstract}
Background: Majority of people with chronic diseases especially having Hypertension and Diabetes have poor Quality Of Life to their therapeutic regimen and life style. It can also result in a variety of complications in body systems associated with undesirable metabolic conditions which affects the quality of life. Objectives: To inquire the effect of satisfaction of Hypertension by exploring Quality Of life in Hypertension and Diabetes. Methodology: A prospective cross sectional study was conducted for six months at tertiary care hospital, Khammam, Telangana. Sample of 200 patients were consented and interviewed to collect the information with an agreement to participate on the subject of socio demographics, physical, mental and behavioral characteristics using a structured questionnaire. Quality Of Life is measured by MINICHAL scale which contains two domains specifically mental domain and somatic domain with 17 questions. It as four potential answers, by way of the scores of $0=$ not at all, 1 =yes, somewhat, 2 =yes, a lot, $3=$ yes very much and sum the points ranging on or after 0-51 International Diabetes Federation indicates the best and worst levels of health, whereas last question be a sign of the overall agreement to participate the patient in study. Results: The scrutiny of this current study found that there is an average quality of life around $61.4 \%$ in hypertension and $44.4 \%$ in hypertension and diabetes. A significant correlation was also established by using chi square test, the $p$ value is $<0.001$. Conclusion: This learning show, self-care is required to avoid the disease and as historical statements further more counselling is needed in patients to get better Quality Of Life.
\end{abstract}

Key words: Chronic diseases, Hypertension, Diabetes, Quality of life, Mental domain, Somatic domain, MINICHAL, Significant Correlation.

\section{INTRODUCTION}

Hypertension is a chronic disease which defines the persistent elevation of arterial blood pressure with forceful blood against walls and it has another name high blood pressure'. Hypertension is one of the noncommunicable disease ${ }^{1}$ which is also called as 'silent killer' and leads to major health issue across the world with $31.1 \%$ [1.39 billion] of global prevalence and this can be estimated using the increase in population by 1.56 billion in $2025 .^{2}$ Hypertension is unavoidable risk factor for heart diseases which have mostly negative impacts on health that leads to morbidity and mortality. ${ }^{3}$ Most of the studies assessed that the hypertension account 9.4 million deaths every year ${ }^{4}$ which makes the life expectancy less about $11.9 \%$. A study stated that the adult population were diagnosed around $26 \%$ of the world wide and it may increase with increase in age.

According to medical perspective diabetes is a group of metabolic diseases characterized by different functions of insulin secreted by pancreas in which the action may be sufficient or insufficient or it may cause resistance which makes acceleration of glucose levels in blood mainly noted as hyperglycemia. ${ }^{5}$ Diabetes is majorly classified into type I and type II along with some new variants like LATENT AUTOIMMUNE DIABETES OF ADULTHOOD / type 1.5
DOI: 10.5530/ijopp.14.2.18

Address for correspondence: K Nikhitha,

Student of Anurag Pharmacy College, Anurag Pharmacy College, Ananthagiri, Suryapet-508206, Telangana, INDIA.

Phone no: +91 08683-272220 Email id: kondanikhitha127@ gmail.com

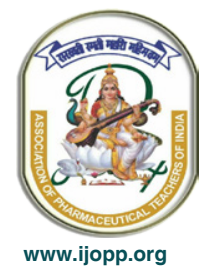


and gestational diabetes. ${ }^{6}$ Some other types which include the monogenic diabetes like MATURITY ONSET DIABETES OF YOUNG that is inherited form of diabetes, cystic fibrosis and other hormonal disorders. INTERNATIONAL DIABETES FEDERATION stated that type II diabetes mellitus is $4^{\text {th }}$ leading cause of death ${ }^{6}$ globally, growing the global epidemic expect to accelerate 171 million cases in $2000^{7}$ and in 2030 it is assessed up to 366 million along with morbidities like micro vascular damage, heart disease, stroke and obesity.

According to $2016 \mathrm{WHO}$, estimated that 422 million people were diagnosed worldwide in $2014^{8}$ and sheer in low and middle income countries. ${ }^{9}$ Micro, macro vascular damage, organs dysfunctions like eye-retinopathy, nervesneuropathy, kidney-nephropathy and hyperlipidemia, ulcer on feet and infection, may also decline in quality of life, risk if heart diseases along with hypertension. Cardio vascular complications are the permanent stressor for diabetes.

In 1948 the world health organization defined quality of life as 'the state of well-being in physically, mentally and psychosocially where there is an absence of disease or infirmity. Quality of life is a subjective concep $\mathrm{t}^{10}$ which maintains the health by physical, mental and socially wellbeing characteristics. Now a day's some treatment and disease conditions are one of the causes to change in lifestyle which affects the HEALTH RELATED QUALITY OF $\mathrm{LIFE}^{11}$ and influence adherence on treatment. It is a key element for disease specific management. ${ }^{12}$ From a past 25 years studies have been stated that Hypertension has a great negative impact on health related quality of life. So in this revision we decided to scrutiny the people in QUALITY OF LIFE in Hypertension and both Hypertension and Diabetes because these are the world most common and snuffled out diseases.

\section{Purpose of the Study}

The need of this study was to assess the quality of life in participant who suffered with long term disease and counsel them to have a handle on the better illness of the disease condition and to their therapeutic management, as well as a clinical pharmacist.

\section{MATERIALS AND METHODS}

\section{Study process}

A prospective cross sectional survey based study was conducted at tertiary care hospital in Khammam within a time period of six months from August 2019 to January 2020 and taking a sample size about 200 patients.

\section{Selection of participants}

Sampling method was used to carry out by approaching the participants to start prolific conversation and followed up during study duration with the inclusion and exclusion criteria.

\section{Inclusion criteria}

Considering the patients above 16 years suffered solely with Hypertension and Diabetes and was diagnosed with either hypertension or diabetes or both. All the patients who were admitted in inpatient department are eligible and were invited and requested to participate in the study with an agreement.

\section{Exclusion criteria}

Patients who were suffering with chronic diseases rather than Hypertension and Diabetes are eliminated. Patients aged below 16 years, pregnant women or postpartum women along with pre diabetic conditions and emergency care patients were excluded.

\section{Source of data}

A structured questionnaire developed to collect information about Socio demographics. Health and medication related characteristics, Clinical diagnosis, Checkups and Daily activities like exercise, Health literacy, Medication adherence questionnaire, Mental and somatic domains of quality of life based. To ensure the data patient medication records, self-reports were taken.

\section{Plan of data}

Collection of data is done by using prepared questionnaire, from each patient demographics details are gathered by conducting an interview of patient/ attendants. The collected data is analyzed by using standard statistical Method and International Diabetes Federation out which of the correlates with results.

\section{Method of assessment}

MINICHAL scale was utilitarian for assessing the quality of life containing two domains namely mental domain and somatic domain with 17 questions, last question International Diabetes Federation indicate the overall agreement to participate the patient in study.

\section{Statistical analysis}

Statistical data was drawn from a structured questionnaire which executed in Microsoft excel 2007 and Chi Square Test is used to determine the significance correlation in Graph Pad Prism 8. 


\section{RESULTS}

\section{Demographics and health related characteristics} of the study patients

The Socio demographics and health related characteristics of the study patients are shown in Table 1-3. The study shows that, out of 200 participants only 176 are eligible to study the quality of life in hypertension and having both hypertension and diabetes in that (Table 1) 105 were solely male $(59.6 \%)$ and participants with the sum average age of adults 20-49(38.2\%) and 50-89(61.7\%) considered as geriatrics as follows below Figure 1.

By assuming the data we found that 156 married (88.6\%), 3 single $(1.7 \%)$ and 17 widowed $(9.7 \%)$. Most of the patients were uneducated $(48.2 \%)$, graduated $(39.2 \%)$ and up to school $(12.5 \%)$. Majority of them are with different other occupations (34\%), self-employed (24.5\%), farmer $(41.4 \%)$ as mentioned in Table 1.

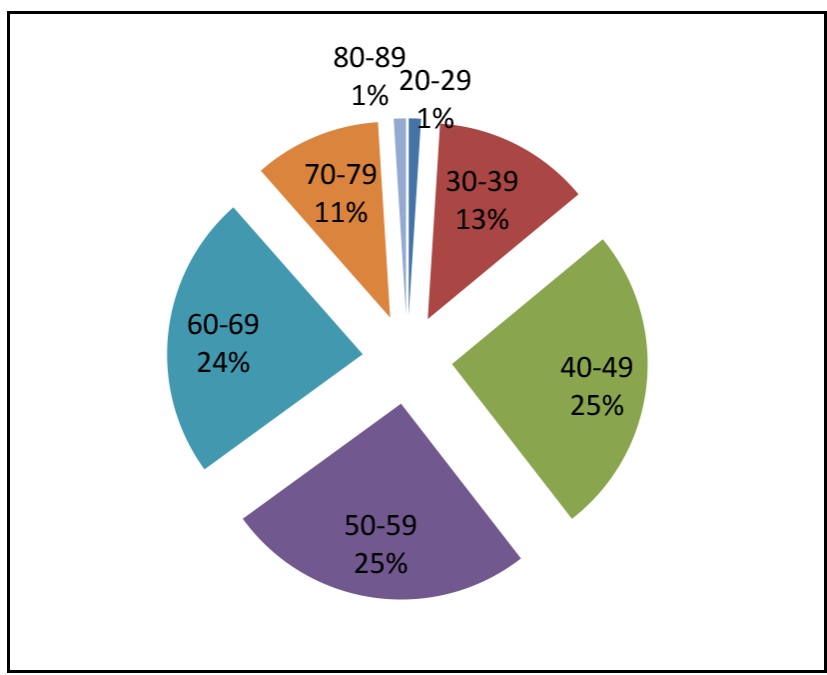

Figure 1: Distribution of Age in Years.

Table 1: Demographic Details of participants with their gender, marital, educational and occupational status.

\begin{tabular}{cccc}
\hline \multicolumn{2}{c}{ Demographic Details } & Number & Percentage \\
\hline \multirow{2}{*}{ Gender } & Male & 105 & $59.6 \%$ \\
& Female & 71 & $40.3 \%$ \\
& Married & 156 & $88.6 \%$ \\
Marital status & Single & 3 & $1.7 \%$ \\
& Widow & 17 & $9.5 \%$ \\
Educational & Uneducated & 85 & $48.2 \%$ \\
status & Up to school & 22 & $12.5 \%$ \\
& Graduated & 69 & $39.2 \%$ \\
& Farmer & 73 & $41.4 \%$ \\
Occupation & Self-employee & 43 & $24.5 \%$ \\
& Others [retired, & & \\
& housewives and & 60 & $34 \%$ \\
& more] & & \\
\hline
\end{tabular}

As in Table 2 participants followed a diet diabetic $(17 \%)$, no diet (38\%), low cholesterol (5.6\%), low salt $(21 \%)$, weight reduction $(9.6 \%)$ and vegetarian $(8.5 \%)$. The participants who have done daily exercise (16.4\%), irregular $(10.2 \%)$, occasional $(7.3 \%)$, no exercise $(65.9 \%)$

\section{Table 2: Distribution of Data Regarding Diet, Exercise,} Alcohol and Smoking Status.

\begin{tabular}{|c|c|c|}
\hline Distribution of Data & Number & Percentage \\
\hline \multicolumn{3}{|c|}{ Diet plan } \\
\hline Diabetic & 30 & $17 \%$ \\
\hline no diet & 67 & $38 \%$ \\
\hline low cholesterol & 10 & $5.6 \%$ \\
\hline low salt & 37 & $21 \%$ \\
\hline weight reduction & 17 & $9.6 \%$ \\
\hline Vegetarian & 15 & $8.5 \%$ \\
\hline \multicolumn{3}{|c|}{ Exercise } \\
\hline Daily & 29 & $16.4 \%$ \\
\hline Irregularly & 18 & $10.2 \%$ \\
\hline Occasionally & 13 & $7.3 \%$ \\
\hline None & 116 & $65.9 \%$ \\
\hline \multicolumn{3}{|c|}{ Alcohol status } \\
\hline Regular & 29 & $16.4 \%$ \\
\hline Irregular & 35 & $19.8 \%$ \\
\hline Occasional & 45 & $25.5 \%$ \\
\hline None & 67 & $38 \%$ \\
\hline \multicolumn{3}{|c|}{ Smoking status } \\
\hline Regular & 42 & $23.8 \%$ \\
\hline Irregular & 30 & $17 \%$ \\
\hline Occasional & 29 & $16.4 \%$ \\
\hline None & 75 & $42.6 \%$ \\
\hline
\end{tabular}

Table 3: Details of Disease, Duration of Disease, Checkups and Drugs Prescribed.

\begin{tabular}{ccc}
\hline Disease & Number & Percentage \\
\hline $\begin{array}{c}\text { Hypertension } \\
\text { Doth Diabetes and hypertension }\end{array}$ & 45 & $25.5 \%$ \\
Duration of disease & $74.4 \%$ \\
1-4 years & 69 & $39.2 \%$ \\
$5-9$ years & 56 & $31.8 \%$ \\
10-14 years & 36 & $20.4 \%$ \\
15-20 years & 15 & $8.5 \%$ \\
& Checkups & \\
Monthly & 33 & $18.7 \%$ \\
every 3-4 months & 26 & $14.7 \%$ \\
every 6 months & 55 & $31.2 \%$ \\
once a year & 62 & $35.2 \%$ \\
Total number of drugs & \\
$<2$ & 45 & $25.5 \%$ \\
$3-<5$ & 75 & $42.6 \%$ \\
$>5$ & 56 & $31.8 \%$ \\
\hline
\end{tabular}


Alcohol consumed patients with regular $(16.4 \%)$, irregularly (19.8\%), occasionally (25.5\%), none (38\%) and smokers were regular $(23.8 \%)$, irregular $(17 \%)$, occasional $(16.4 \%)$, none $(42.6 \%)$.

Participants suffered with a disease of Hypertension (25.5\%) and Diabetes and Hypertension (74.4\%). Patients experiencing the disease from 1 -4 years (39.2\%), 5-9 years (31.8\%), 10-14 years $(20.4 \%)$ and 15 -20years $(8.5 \%)$. Participants visited hospital for checking (18.7\%) monthly, (14.7\%) every 3-4 months, (31.2\%) every 6 months, $(35.2 \%)$ once in a year. Among these $(25.5 \%)$ participants were prescribed with $<2$ drugs, $(42.6 \%) 3-<5$ drugs and $(31.8 \%)>5$ drugs as looking into Table 3 .

\section{Determination of Quality of Life}

According to MINICHAL scale the mental domain consists of $0-27$ points in which somatic domain contain 0-21 points. Considering the four possible answers with the scores of $0=$ not at all, $1=y e s$, somewhat, $2=y e s$, a lot, $3=$ yes, very much and sum the points ranging from 0-51. International Diabetes Federation indicates the best and worst levels of health. Here the distribution of responses of Hypertension, Hypertension and Diabetes in MINICHAL was given in below Tables clearly. By using chi square test analysis a significant correlation was found in both domains with the effects $(P<0.001)$ as shown in Tables 4-7.

By overall participant's data has a score range of International Diabetes Federation individual response to the questions (45) hypertension patients with (9) best, (20) average and (16) poor quality of life. Whereas in both (131) Hypertension and Diabetes containing patients had (26) better, (80) average and (25) poor QUALITY OF LIFE was given in Table 8.

\section{DISCUSSION}

Chronic diseases like hypertension and diabetes are included in our study to measure the quality of life in hypertension only because researches with many of studies done on Health Related Quality of life on diabetes but a very rare of them are hypertension and it also probable to take a broad view of quality of life in individual hypertension, diabetes mellitus and in both cases of hypertension and diabetes mellitus. Although, they didn't even have any truthful conclusion with low quality of life and most of them settled for additional counselling is indispensable. In certain study specified that - previous studies have exposed that physical domain in Quality of life declines with enlarged prevalence of chronic disease and advanced age. Mental domain in

\begin{tabular}{|c|c|c|c|c|c|}
\hline Mental domain & $\begin{array}{c}\text { Not at all } \\
0\end{array}$ & $\begin{array}{c}\text { Yes, } \\
\text { somewhat } 1\end{array}$ & $\begin{array}{c}\text { Yes, a lot } \\
2\end{array}$ & $\begin{array}{c}\text { Yes, very much } \\
3\end{array}$ & Mean \pm SD \\
\hline Poor sleep & 9 & 15 & 11 & 10 & $1.48 \pm 1.06$ \\
\hline Difficulty to maintain social relationships & 22 & 9 & 7 & 7 & $0.97 \pm 1.15$ \\
\hline Difficulty in interaction & 20 & 11 & 7 & 7 & $1.02 \pm 1.13$ \\
\hline Not playing useful role & 35 & 6 & 2 & 2 & $0.35 \pm 0.77$ \\
\hline Unable to make decision & 20 & 10 & 8 & 7 & $1.04 \pm 1.14$ \\
\hline Felt distressed continuously & 9 & 16 & 12 & 8 & $1.42 \pm 1.01$ \\
\hline Life is a struggle & 7 & 9 & 20 & 9 & $1.68 \pm 0.98$ \\
\hline Not enjoying daily activities & 20 & 10 & 7 & 8 & $1.06 \pm 0.16$ \\
\hline Felt worn out & 20 & 11 & 7 & 7 & $1.02 \pm 1.12$ \\
\hline
\end{tabular}

$p<0.0001$

Table 5: Somatic domain - Quality Of Life in Hypertension.

\begin{tabular}{|c|c|c|c|c|c|}
\hline Somatic domain & $\begin{array}{c}\text { Not at all } \\
0\end{array}$ & $\begin{array}{c}\text { Yes, } \\
\text { somewhat } 1\end{array}$ & $\begin{array}{c}\text { Yes, a lot } \\
2\end{array}$ & $\begin{array}{c}\text { Yes, very much } \\
3\end{array}$ & Mean \pm SD \\
\hline Felt sick & 5 & 19 & 6 & 15 & $1.68 \pm 1.06$ \\
\hline Felt breathless & 14 & 18 & 7 & 6 & $1.11 \pm 1.01$ \\
\hline Swollen ankles & 16 & 12 & 10 & 7 & $1.17 \pm 1.09$ \\
\hline Frequent urination & 7 & 13 & 15 & 10 & $1.62 \pm 1.01$ \\
\hline Dry mouth & 7 & 21 & 15 & 2 & $1.26 \pm 0.78$ \\
\hline Chest pain without exertion & 13 & 23 & 3 & 6 & $1.04 \pm 0.96$ \\
\hline Tingling and numbness & 9 & 24 & 10 & 2 & $1.11 \pm 0.78$ \\
\hline Quality of life affected by hypertension and its treatment & 15 & 17 & 11 & 2 & $1.00 \pm 0.87$ \\
\hline
\end{tabular}


Table 6: Mental domain - Quality Of Life in Hypertension and Diabetes.

\begin{tabular}{ccccccc} 
Mental domain & Not at all & Yes, & Yes, a lot & Yes, very much & Mean \pm SD \\
\hline Poor sleep & $\mathbf{0}$ & 40 & 53 & 23 & 15 & $1.21 \pm 0.95$ \\
somewhat & $\mathbf{2}$ & 2 & 0 & $0.11 \pm 0.36$ \\
Difficulty to maintain social relationships & 121 & 8 & 38 & 2 & 5 & $0.43 \pm 0.71$ \\
Difficulty in interaction & 86 & 26 & 6 & 0 & $0.24 \pm 0.46$ \\
Not playing useful role & 103 & 15 & 57 & 22 & 1 & $0.24 \pm 0.57$ \\
Unable to make decision & 34 & 68 & 24 & 14 & $1.18 \pm 0.97$ \\
Felt distressed continuously & 25 & 56 & 3 & 1 & $1.20 \pm 0.87$ \\
Life is a struggle & 71 & 60 & 9 & 6 & $0.50 \pm 0.58$ \\
Not enjoying daily activities & 56 & & & $0.74 \pm 0.78$ \\
Felt worn out & & &
\end{tabular}

$p<0.0001$

Table 7: Somatic domain - Quality Of Life in Hypertension and Diabetes.

\begin{tabular}{|c|c|c|c|c|c|}
\hline Somatic domain & $\begin{array}{c}\text { Not at all } \\
0\end{array}$ & $\begin{array}{c}\text { Yes, } \\
\text { somewhat } 1\end{array}$ & $\begin{array}{l}\text { Yes, a lot } \\
2 \\
\end{array}$ & $\begin{array}{c}\text { Yes, very much } \\
\mathbf{3} \\
\end{array}$ & Mean \pm SD \\
\hline Felt sick & 25 & 47 & 30 & 29 & $1.50 \pm 1.02$ \\
\hline Felt breathless & 46 & 50 & 15 & 20 & $1.07 \pm 1.03$ \\
\hline Swollen ankles & 63 & 33 & 13 & 22 & $0.95 \pm 1.10$ \\
\hline Frequent urination & 23 & 55 & 31 & 22 & $1.37 \pm 0.95$ \\
\hline Dry mouth & 30 & 60 & 21 & 20 & $1.20 \pm 0.96$ \\
\hline Chest pain without exertion & 40 & 54 & 14 & 23 & $1.10 \pm 1.02$ \\
\hline Tingling and numbness & 32 & 67 & 24 & 8 & $1.05 \pm 0.82$ \\
\hline $\begin{array}{c}\text { Quality of life affected by hypertension and its } \\
\text { treatment }\end{array}$ & 48 & 58 & 21 & 4 & $0.86 \pm 0.79$ \\
\hline
\end{tabular}

$p<0.0001$

Table 8: Data of Quality Of Life International Diabetes Federationividual Responses in Participants ( $n=176)$.

\begin{tabular}{ccc}
\multicolumn{3}{c}{ Hypertension } \\
\hline Parameter & $\mathbf{N}$ & $\mathbf{N} \%$ \\
Better & 9 & $20 \%$ \\
Average & 20 & $44.5 \%$ \\
Poor & 16 & $35.5 \%$ \\
& Hypertension And Diabetes & \\
Better & 26 & $19.84 \%$ \\
Average & 80 & $61.08 \%$ \\
Poor & 25 & $19.08 \%$ \\
\hline
\end{tabular}

Health Related Quality of life has been shown to remain more stable - even with advancing age and increased chronic conditions.

Here indeed assessing the Quality of life not merely in hypertension but also in both hypertension and diabetes in order to review the effect of interaction of disease type and adherence level on Quality of life domains. However by looking into the Table 4, 5 patients with chronic diseases (especially diabetes and hypertension) have high in somatic parameter because of their declined disease condition and it may be due to several other factors like medication taking pattern use, diet, physical stress, long term illness, educational, occupational status and some other habitual as in previous mentioned study.

In our study patients solely hypertension or both having hypertension and diabetes in Table 6 had a high average Quality of life which has a significant correlation $(P=<0.0001)$ with the individual disease condition. As shown in Figure 1 the ages of the participants were geriatrics 50-89 (61.7\%) suffered in the company of long term disease, seasonal disease [dengue fever] because of having less ability to tolerate environmental condition and also recover their health. Other factors like educational status, diet, physical stress and all that affects the Quality of life because many of them were with poor acquaintance towards the diet, medication use and work plan, as most of them were housewives, retired officers(34.4\%), (41.4\%) farmers (Table 1). Majority of the subjects (Table 2) were non-alcoholic $(38 \%)$ and non-smokers (42.6\%) followed to improve Quality of life respectively.

Low and high levels of Quality of life are reported because most of the participants suffered with both diabetes and hypertension (74.4\%) as Table 3 shows diabetic patients having more risk on behalf of hypertension, number of drugs prescribed in each prescription are 3-5 drugs in 
$(42.6 \%)$ of subjects due to multiple disease conditions, duration of disease $1-4$ years $(39.2 \%)$, 5-9years (31.8\%) with lack of attentiveness, knowledge, carelessness which prolongs the disease duration/condition.

We notice that still some graduates, farmers were with lack of wakefulness about quality of life are more prone to suffer with co morbidities like cardiovascular disease, kidney related diseases as chronological order. In this paper even we cited a small group of people although gained a lot of information to assess the overall effect or cause of the disease or people suffered with common diseases and it is also an another way of developing epidemiological status if needed. Observably, there is a lack of interest in people to boost their immunity towards health, environment and social status. In order to educate or aware them advance, a clinical pharmacist is needed who plays an essential role in delivering good medication adherence practices in chronic disease patients or any other condition

In current study it is to be specifying in Table 1, farmers and other occupations (34\%) were aware of disease is experimental through their understanding levels related to medication, disease complications and health fitness. Finally we reported that, evaluation of the average quality of life around $61.08 \%$ participants with both diabetes and hypertension and in hypertension $44.5 \%$ (Table 6 ) as noticed as, there is modest of variation in patients than previous studies reports who followed the low level of health quality.

\section{CONCLUSION}

By this study we concluded self-care is needed to prevent the hypertension and diabetes related morbidities and mortality. Still some participants were unaware of true causes of diabetes and hypertension. In fact there is some lack of trust in physician, health providers or other health care professionals and acceptance of folk's beliefs. To avoid these health care professionals should monitor the patient on their health illness and strictly suggest the patients about their disease, drugs and life style modifications courteously in order to maintain their better quality of life and make them sticky adhere to their medication.

\section{Ethical Approval}

The study was approved by the institutional ethical committee on APC/IEC/03/2019.

\section{ACKNOWLEDGEMENT}

The authors like to thank Dr. M. Chinna Eshwaraiah,
Principal of Anurag Pharmacy College for granting us the necessary permission for the study. The authors also thank all the faculty of Anurag Pharmacy College for their constant support and guidance.

\section{CONFLICT OF INTEREST}

The authors declare that they have no conflict of interest.

\section{SUMMARY}

Self-care is considerably necessary to stop the hypertension and diabetes morbidities and mortality traces despite the average quality of life is identified in both the chronic diseases. A significant correlation is found between the effect of outcome and parameters where the study brought some awareness to ameliorate the consciousness of disease, health quality and adherence to medications.

\section{REFERENCES}

1. Lee GK, Wang HH, Liu KQ, Cheung Y, Morisky DE, Wong MC. Determinants of medication adherence to antihypertensive medications among a Chinese population using Morisky Medication Adherence Scale. Plosone. 2013;8(4):62775.

2. Saqlain M, Riaz A, Malik MN, Khan S, Ahmed A, Kamran S, et al. Medication Adherence and its Association with Health Literacy and Performance in Activities of Daily Livings among Elderly Hypertensive Patients in Islamabad, Pakistan. Medicina. 2019;55(5):163.

3. Riaz H, Sadeeqa S, Sultana M. Hypertension-related knowledge, medication adherence and health-related quality of life among hypertensive patients in Islamabad, Pakistan. Tropical Journal of Pharmaceutical Research. 2019;18(5):1123-32.

4. Khayyat SM, Alhazmi RS, Mohamed MM, Hadi MA. Predictors of medication adherence and blood pressure control among Saudi hypertensive patients attending primary care clinics: A cross-sectional study. PloS One. 2017;12(1):0171255.

5. Timar R, Velea I, Timar B, Lungeanu D, Oancea C, Roman D, et al. Factors influencing the quality of life perception in patients with type 2 diabetes mellitus. Patient Preference and Adherence. 2016;10:2471.

6. Gupta L, Khandelwal D, Lal PR, Gupta Y, Kalra S, Dutta D. Factors Determining the Success of Therapeutic Lifestyle Interventions in Diabetes-Role of Partner and Family Support. European Endocrinology. 2019;15(1):18.

7. Singh C, Crawford K, Willey S, Hall H, Harder K, Plummer V, et al. Medication adherence among people of International Diabetes Federation an ethnicity living with chronic disease following migration to Australia. Collegian. 2020;27(2):17984

8. Wild S, Roglic G, Green A, Sicree R, King H. Global prevalence of diabetes: Estimates for the year 2000 and projections for 2030. Diabetes Care. 2004;27(5):1047-53.

9. Poljicanin T, Ajdukovic D, Sekerija M, Pibernik-Okanovic M, Metelko Z, Mavrinac V. Diabetes mellitus and hypertension have comparable adverse effects on health-related quality of life. BMC Public Health. 2010;10(1):12.

10. Trevisol DJ, Moreira LB, Fuchs FD, Fuchs SC. Health-related quality of life is worse in International Diabetes Federation individuals with hypertension under drug treatment: Results of population-based study. Journal of Human Hypertension. 2012;26(6):374.

11. Erickson SR, Williams BC, Gruppen LD. Relationship between symptoms and health-related quality of life in patients treated for hypertension. Pharmacotherapy: The Journal of Human Pharmacology and Drug Therapy. 2004;24(3):344-50.

12. Sushma P, Gali NC, Badhela H, Palinga A, Lakshmi KR. Evaluation of medication adherence in type-2 diabetic patients in tertiary care hospital. International Journal of Research and Analytical Reviews. 2018;5(4):921-9. 